\title{
MIRÍDEOS NEOTROPICAIS. CCCXCVIII. GÊNERO E ESPÉCIES NOVOS DO SUL DO BRASIL (HEMIPTERA)
}

\author{
José C.M. Carvalho ${ }^{1,2}$ \\ Luiz A.A. Costa ${ }^{1}$
}

\begin{abstract}
NEOTROPICAL MIRIDAE. CCCXCVIII. NEW GENUS AND SPECIES FROM SOUTH OF BRAZIL (HEMIPTERA). A new genus and five new species of Hemiptera, Miridae, from south of Brazil are described as follows: Derophthalma vittinotata, sp.n.; Parachius pallidus, sp.n.; Paranacoris, gen.n.; Paranacoris vertexalbus, sp.n.; Tropidosteptes vittiscutellatus, sp.n.; Tupiniquinus alboantennatus, sp.n. Illustrations of habitus and male genitalia are included. KEY WORDS. Hemiptera, Miridae, new taxa, Brazil
\end{abstract}

Um novo gênero e cinco espécies novas do sul do Brasil são descritos. O material foi gentilmente enviado para estudo pelo Dr. Joseph C. Schaffner, Departamento de Entomologia da Universidade do Texas A \& M, a quem os autores agradem.

As medidas são em milímetros e foram desenhadas por Paulo Roberto Nascimento.

\section{Derophthalma vittinotata, sp.n.}

Figs 1-4

Holótipo fêmea. BRASIL: Santa Catarina, Seara (Nova Teutônia), $27^{\circ}$ $11^{\prime} \mathrm{N}$ e $52^{\circ} 23^{\prime} \mathrm{W}$, Fritz Plaumann leg., na Coleção do Museu Nacional, Rio de Janeiro. Parátipos: um macho, uma fêmea, idem, na coleção do primeiro autor.

Diagnose. Reconhecível pelas faixas brancas longitudinais do pronoto, pelo escutelo pálido na linha mediana com ápice pálido e pela morfologia da genitália do macho.

Descrição. Corpo: comprimento 5,2; largura 1,9. Cabeça: comprimento 9,6; largura 1,2; vértice 0,64. Antena: comprimento segmento I 0,5; II 1,4; III 0,7; IV 0,4. Pronoto: comprimento 1,2; largura na base 1,8. Cúneo: comprimento 0,60 ; largura na base 0,60 (holótipo).

Coloração geral do corpo castanho-escuro; cabeça com olhos pretos, vértice e fronte castanhos, clípeo e loros negros; antenas com segmento II próximo da base castanho, o restante negro; rostro castanho, negro no ápice. Pronoto com colar bem definido, calos baixos, margem posterior largamente

1) Museu Nacional do Rio de Janeiro, Quinta da Boa Vista, 20940-040 Rio de Janeiro, Rio de Janeiro, Brasil.

2) Bolsista do CNPq. 

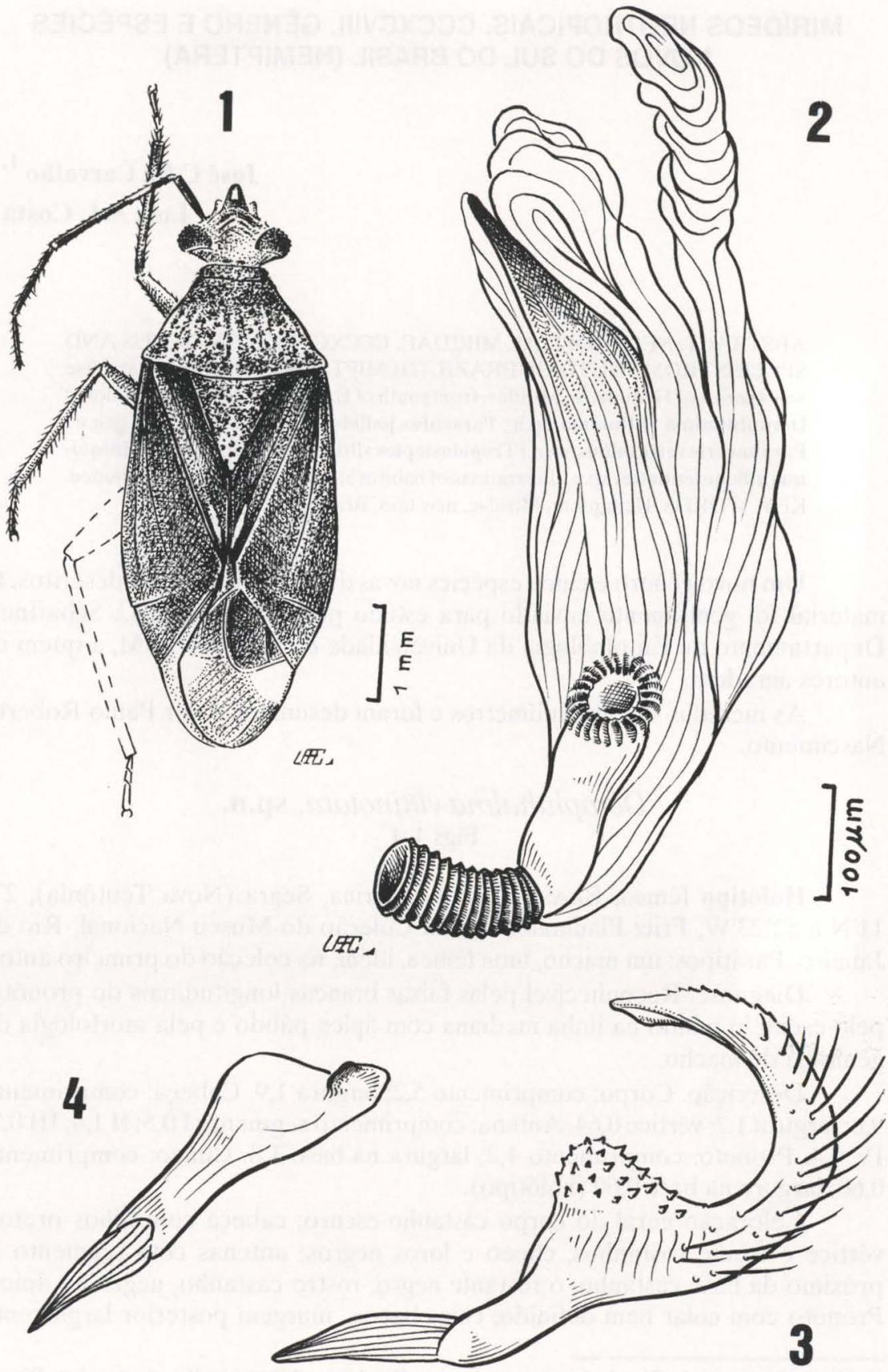

Figs 1-4. Derophthalma vittinotata, sp.n. (1) Fêmea, corpo inteiro; (2) vésica do macho; (3) parâmero esquerdo; (4) parâmero direito. 
curva, disco com linha mediana e duas faixas claras de cada lado, no meio; escutelo com manchas pequenas, linha mediana e ápice largamente brancos. Hemiélitros com embólio visível, membrana fusca, nervuras brancas e duas manchas claras na porção extrareolar. Lado inferior do corpo com xifo, mesosterno no meio, propleura inferiormente, orifício ostiolar e segmento II do abdome pálidos. Rostro alcançando as coxas medianas.

Macho. Com tamanho e coloração iguais aos da fêmea, vértice 0,48.

Genitália. Vésica (Fig. 2) com espículo central e lobos membranosos, canal seminal distal curto, gonóporo secundário pequeno. Parâmero esquerdo (Fig. 3) com lobo sub-basal coberto de espinhos, pêlos longos na face dorsal, curvo, extremidade apical fendida. Parâmero direito (Fig. 4) pequeno, dilatado subapicalmente e terminando em ponta.

Distribuição geográfica. BRASIL: Santa Catarina, Seara.

$\mathrm{O}$ nome específico é alusivo à presença de faixas claras no disco do pronoto.

\section{Parachius pallidus, sp.n.}

Figs 5-9

Holótipo fêmea. BRASIL: Santa Catarina, Seara (Nova Teutônia), $27^{\circ}$ $11^{\prime} \mathrm{N}$ e $52^{\circ} 23^{\prime} \mathrm{W}$, Fritz Plaumann leg., na Coleção do Museu Nacional, Rio de Janeiro. Parátipos: um macho, idem, na coleção do primeiro autor.

Diagnose. Reconhecível pela coloração pálida e pela morfologia da genitália do macho.

Descrição. Corpo: comprimento 3,8; largura 0,9. Cabeça: comprimento 0,3 ; largura 0,5 ; vértice 0,24 . Antena: comprimento segmento I 0,$3 ;$ II 0,$7 ;$ III 0,6 ; IV 0,3. Pronoto: comprimento 0,5; largura na base 0,9. Cúneo: comprimento 0,62 ; largura na base 0,30 (holótipo).

Coloração geral do corpo pálida.

Macho. Da mesma cor e dimensões que a fêmea, vértice 0,22.

Genitália. Vésica (Fig. 6) com três espinhos apicais, um só lobo, canal seminal distal longo, vista dos espinhos apicais (Fig. 7). Parâmero esquerdo (Fig. 8) fortemente recurvo, com ponta afilada, pêlos no lobo sub-basal. Parâmero direito (Fig. 9) pequeno, longo, dilatado apicalmente, ápice em ponta.

Distribuição geográfica. BRASIL: Santa Catarina, Seara.

Diferencia-se das demais espécies do gênero pela coloração do corpo e pela morfologia da genitália do macho.

$\mathrm{O}$ nome específico é alusivo à sua coloração.

\section{Paranacoris, gen.n.}

Orthotylinae, Orthotylini, corpo liso, revestido por pêlos muito curtos, pronoto chagrén.

Cabeça com olhos contíguos ao pronoto, vértice com margem posterior 


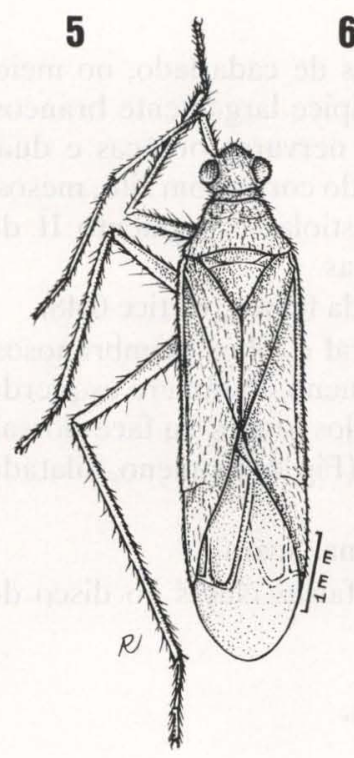

6
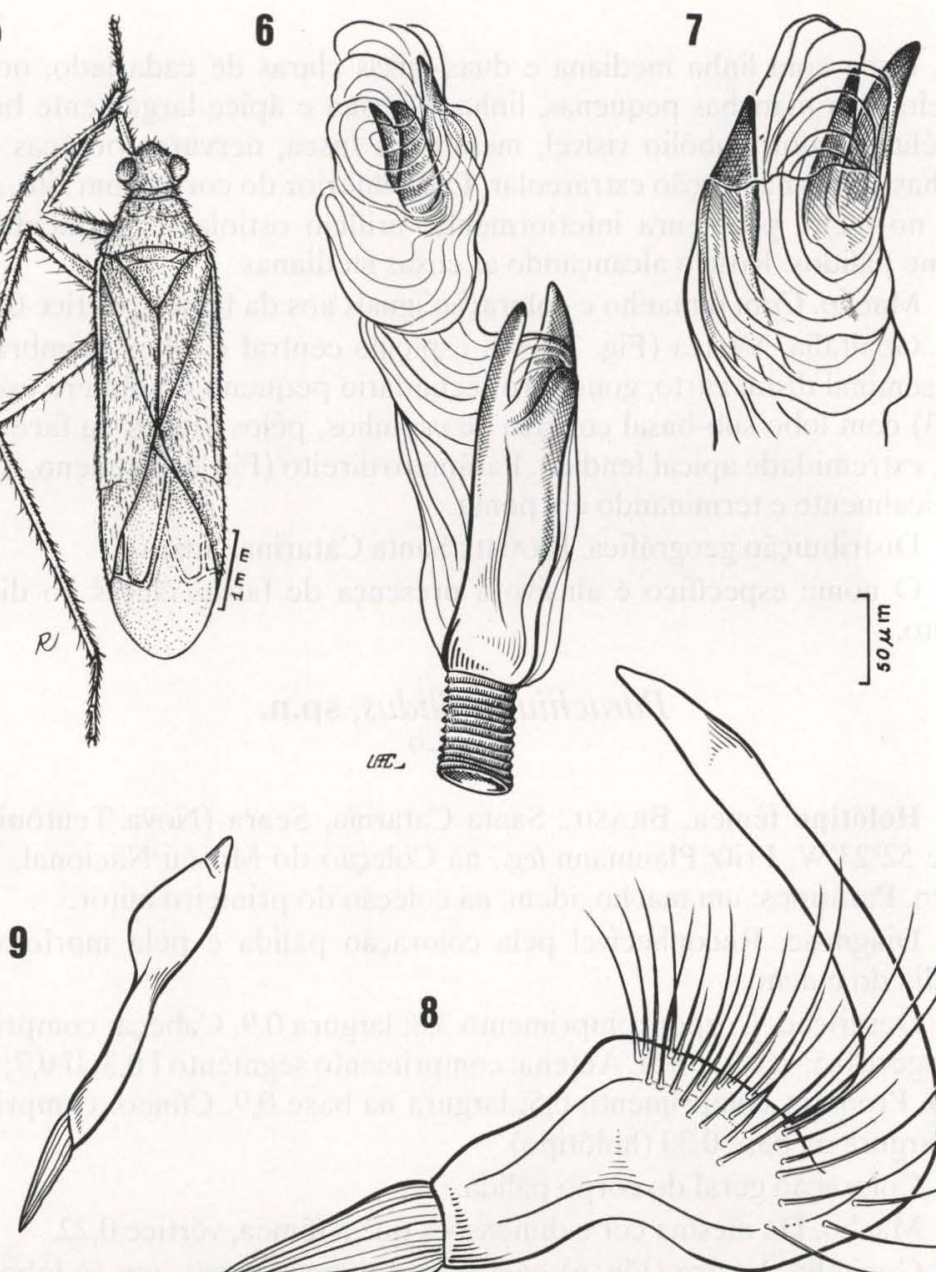

8

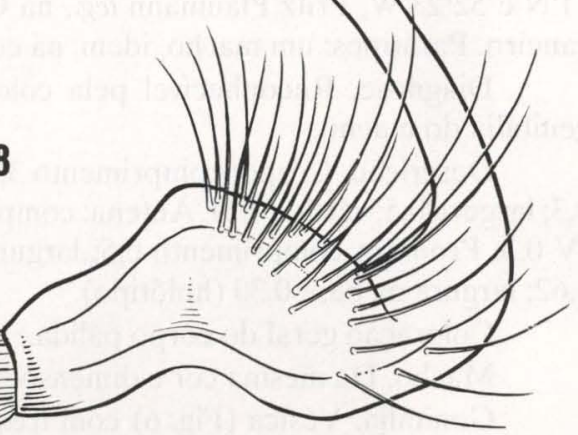

Figs 5-9. Parachius pallidus, sp.n. (5) Fêmea, corpo inteiro; (6) vésica; (7) espinhos apicais da vésica; (8) parâmero esquerdo; (9) parâmero direito.

engrossada, redonda, fronte plana, clípeo pontudo, segmento I da antena com cerdas eretas, cerca de três vezes mais curto que o II, possuindo numerosos pêlos mais curtos que sua largura, levemente engrossado para o ápice; rostro alcançando as coxas medianas. Cabeça pontuda para a frente. Pronoto chagrén com colar deprimido, calos obsoletos, lisos, margem posterior do disco reta; escutelo plano. Hemiélitros transparentes, exocório e cúneo mais claros; membrana fusca, transparente. Lado inferior do corpo com pilosidade nas pleuras e lados do mesosterno, oríficio ostiolar bem determinado, tíbias III com espinhos equivalentes à sua grossura, abdome piloso.

Espécie tipo: Paranacoris vertexalbus, sp.n. 
Diferencia-se dos demais gêneros da subfamília por ter a antena II curta, pelo lado inferior e abdome piloso.

O nome genérico é alusivo ao estado do Paraná, Brasil.

\section{Paranacoris vertexalbus, sp.n.}

Figs 10-13

Holótipo macho. BRASIL: Paraná, Bocaiuva do Sul, 14 September 1984, W.E. Clark, na Coleção do Museu Nacional, Rio de Janeiro. Parátipo. Uma fêmea, mesmas indicações que o tipo, na coleção do primeiro autor.

Diagnose. Reconhecível por ter a cabeça e pronoto pretos, com vértice branco e pela morfologia da genitália do macho.

Descrição. Corpo: comprimento 3,2; largura 1,3. Cabeça: comprimento 0,3 ; largura 0,7; vértice 0,34. Antena: comprimento segmento I 0,2; II 0,6; III 0,2; IV ausente. Pronoto: comprimento 0,4 ; largura na base 1,1. Cúneo: comprimento 0,42 ; largura na base 0,30 (holótipo).

Coloração geral do corpo preta e castanho-clara; cabeça preta com vértice e parte posterior dos olhos brancos; antenas com segmento I e metade do II castanho-claros, restante reto; rostro preto. Pronoto preto, colar deprimido, calos obsoletos, margem posterior reta; escutelo preto. Hemiélitros castanho-claros, embólio levemente mais claro, ápice do cório brancacento, cúneo da mesma cor do embólio; membrana fusca transparente. Lado inferior do corpo preto com mancha branca na parte posterior da propleura, coxas para o ápice; fêmures (o III com pontos negros externamente), tíbias III com pontos pretos na base dos espinhos (inferiormente fundidos); tarsos com segmento II castanho.

Genitália. Pênis (Fig. 11) do tipo Phylini, dobrado sob si mesmo no meio do ápice afilado. Parâmero esquerdo (Fig. 12) com pêlos dorsais longos, as duas pontas praticamente iguais. Parâmero direito (Fig. 13) menor, dilatado na região apical, terminando em ponta.

Fêmea. Com as mesmas dimensões do macho, vértice 0,30. Antena I (exceto extrema base), segmento I do rostro, base do segmento III brancos, fêmures III castanho-claros.

Distribuição geográfica. BRASIL: Paraná, Bocaiuva do Sul.

O nome específico é alusivo ao vértice branco.

\section{Tropidosteptes vittiscutelatus, sp.n.}

Figs 14-17

Holótipo macho. BRASIL: Santa Catarina, Seara (Nova Teutônia), July, $27^{\circ} 11^{\prime} \mathrm{N}$ e $52^{\circ} 23^{\prime} \mathrm{W}$, Fritz Plaumann leg., na Coleção do Museu Nacional, Rio de Janeiro. Parátipos: macho e fêmea, idem, na coleção do primeiro autor.

Diagnose. Reconhecível por uma faixa negra no escutelo e pela morfologia da genitália do macho. 

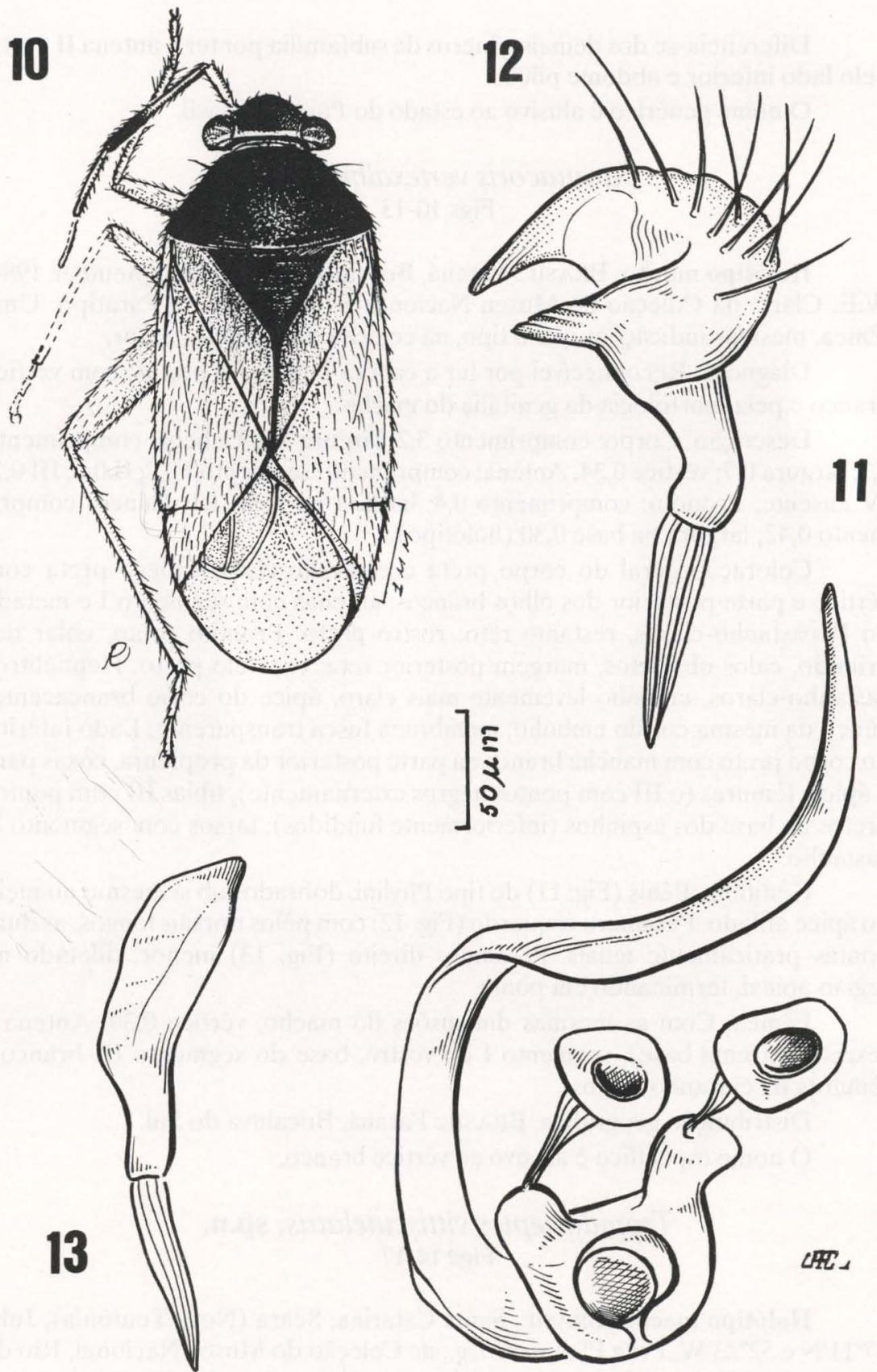

Figs 10-13. Paranacoris vertexalbus, sp.n. (10) Macho, corpo inteiro; (11) pênis; (12) parâmero esquerdo; (13) parâmero direito. 


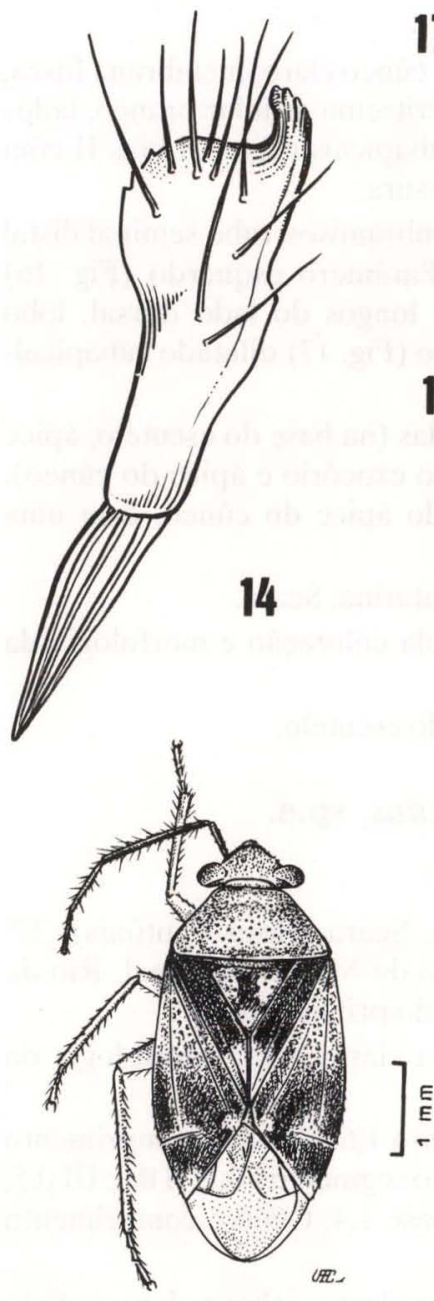

17

15
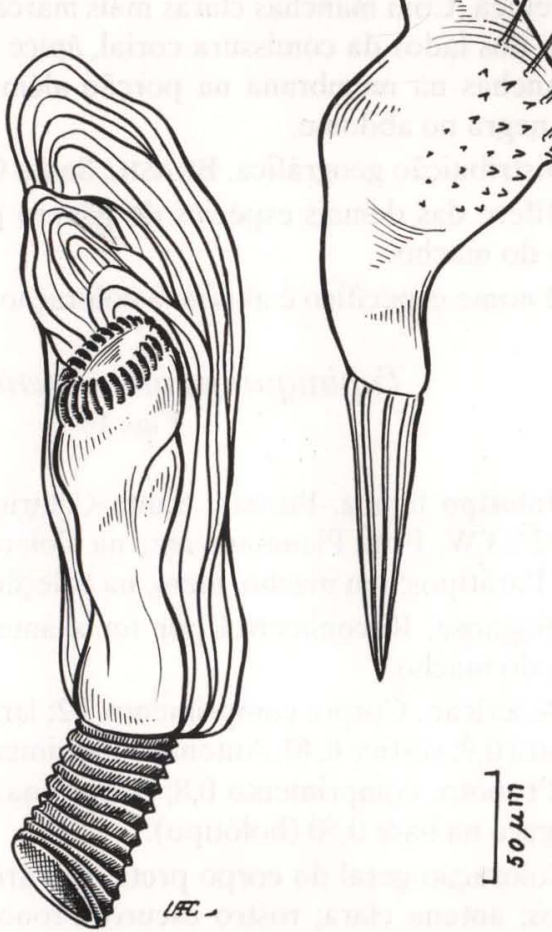

Figs 14-17. Tropidosteptes vittiscutelatus, sp.n. (14) Macho, corpo inteiro; (15) vésica; (16) parâmero esquerdo; (17) parâmero direito.

Descrição. Corpo: comprimento 4,4; largura 2,0. Cabeça: comprimento 0,2 ; largura 0,9 ; vértice 0,40 . Antena: comprimento segmento I 0,5 ; II 1,$4 ;$ III 0,6 ; IV 0,3. Pronoto: comprimento 0,7; largura na base 1,2. Cúneo: comprimento 0,60 ; largura na base 0,50 (holótipo).

Coloração geral do corpo castanha com áreas escuras; clípeo negro, olhos vermelhos; antenas negras; rostro castanho, ápice escuro. Pronoto com colar, calos obsoletos, escutelo claro, com uma faixa mediana na base negra; mesoscuto escuro. Hemiélitros negros, com clavo (exceto ápice), claro na porção basal, negro na porção apical, com uma mancha clara ao lado da 
comissura corial e no ápice do exocório, ápice do cúneo claro; membrana fusca, nervuras pálidas. Lado inferior do corpo com peritrema ostiolar branco, lados do mesosterno negros, fêmures III com anéis subapicais negros, tíbias II com granulações e espinhos tão longos como sua grossura.

Genitália. Vésica (Fig. 15) com lobos, membranosos, tubo seminal distal alargado no ápice, onde possui o gonóporo. Parâmero esquerdo (Fig. 16) fortemente curvo, ápice explanado, com pêlos longos do lado dorsal, lobo sub-basal coberto por espinhos. Parâmero direito (Fig. 17) dilatado subapicalmente, com pêlos e ápice recurvos.

Fêmea. Com manchas claras mais marcadas (na base do escutelo, ápice do clavo, dos lados da comissura corial, ápice do exocório e ápice do cúneo), duas manchas na membrana na porção além do ápice do cúneo, com uma mancha negra no abdome.

Distribuição geográfica. BRASIL: Santa Catarina, Seara.

Difere das demais espécies do gênero pela coloração e morfologia da genitália do macho.

O nome específico é alusivo à coloração do escutelo.

\section{Tupiniquinus alboantennatus, sp.n.} Figs 18-21

Holótipo fêmea. BRASIL: Santa Catarina, Seara (Nova Teutônia), $27^{\circ}$ $11^{\prime} \mathrm{N}$ e 52 $23^{\prime} \mathrm{W}$, Fritz Plaumann leg., na Coleção do Museu Nacional, Rio de Janeiro. Parátipos: um macho, idem, na coleção do primeiro autor.

Diagnose. Reconhecível por ter a antena clara e pela morfologia da genitália do macho.

Descrição. Corpo: comprimento 3,2; largura 1,6. Cabeça: comprimento 0,$2 ;$ largura 0,9 ; vértice 0,40 . Antena: comprimento segmento I 0,$2 ;$ II 0,$9 ;$ III 0,5 ; IV 0,3. Pronoto: comprimento 0,8 ; largura na base 1,4. Cúneo: comprimento 0,50; largura na base 0,50 (holótipo).

Coloração geral do corpo preta com áreas claras; cabeça clara ao lado dos olhos; antena clara; rostro escuro. Pronoto com colar deprimido, calos obsoletos, margem posterior largamente arredondada, preto, com escamas brancas. Hemiélitros com cinco linhas oblíquas de escamas prateadas, mais largo posteriormente, incisão cuneal profunda, cúneo mais ou menos arredondado no ápice; membrana fusca. Lado inferior do corpo da mesma cor do superior, com propleura branca na margem inferior e posterior, peritrema ostiolar branco, fêmur preto-avermelhado, tíbias com faixa branca subapical.

Macho. Com dimensões iguais à fêmea.

Genitália. Vésica (Fig. 19) complicada, veja figura, gonóporo secundário do tipo Orthotylini. Parâmero esquerdo (Fig. 20) também complicado, com um dente mediano e duas pontas: a maior longa e fina, a menor no fim do lobo. Parâmero direito (Fig. 21) bipartido, numa das pontas serreado e noutra com pêlos e terminado em ponta bipartida. 

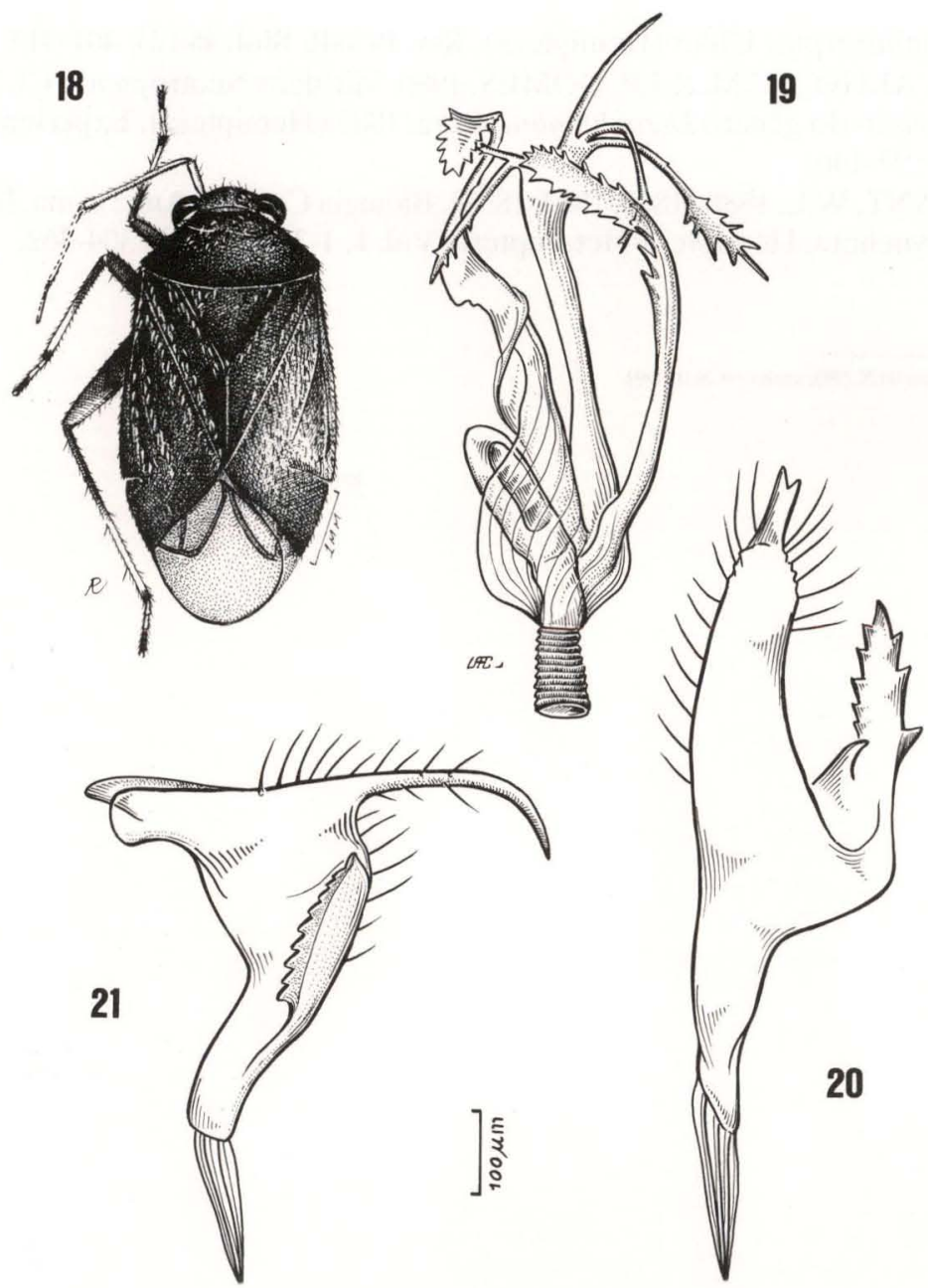

Figs 18-21. Tupiniquinus alboantennatus, sp.n. (18) Fêmea, corpo inteiro; (19) vésica; (20) parâmero esquerdo; (21) parâmero direito.

Distribuição geográfica. BRASIL: Santa Catarina, Seara.

Diferencia-se da outra espécie do gênero (Tupiniquinus aquamosus Carvalho, 1984) pela coloração e pela morfologia da genitália do macho.

O nome específico é alusivo à coloração das antenas.

\section{REFERÊNCIAS BIBLIOGRÁFICAS}

CARVALHO, J.C.M. 1984. Mirídeos Neotropicais, CCXLI: Cinco gêneros e sete espécies novos (Hemiptera). Rev. Brasil. Biol. 44 (1): 47-57.

- 1986. Mrídeos Neotropicais, CCLXX: Espécies Regionais do gênero 
Tropidosteptes Uhler (Hemiptera). Rev. Brasil. Biol. 46 (2): 401-413.

CARVALHO, J.C.M. \& I.P. GOMES. 1980. Mirídeos Neotropicais, CCXVIII:

Revisão do gênero Derophthalma Berg, 1883 (Hemiptera). Experientiae 26 (5): 93-146.

DISTANT, W.L. $1880(1883,1884,1893)$. Biologia Centrali Americana. Insecta.

Rhynchota, Hemiptera-Heteroptera. Vol. 1: 1-302, Suppl.: 304-462.

Recebido em 06.X.1993; aceito em 26.III. 1994. 